DOI: 10.20472/IAC.2018.935.020

\title{
NINO INJGIA
}

Iv. Javakhishvili Tbilisi State University, Georgia

\section{CASE STUDY OF TSALKA, GEORGIA: SOCIAL IDENTITY AND ADAPTATION TO A NEW LIVING ENVIRONMENT}

\begin{abstract}
:
Migration is associated with adaptation problems and has a great impact on migrated people's identity and quality of life. This case study explains how adaptation process is related to social identity transformation among eco-migrants settled in Tsalka, Georgia. Tsalka is a town in eastern Georgia with a multi-ethnic population (Georgians, Armenians, Greeks, and Azerbaijanis). It has been a location where eco-migrants from mountain regions of Georgia rushed into and settled in 1997-2006. 32 eco-migrants from 20 households participated in in-depth interviews. The results showed that there are two types of eco-migrants: with state shelter and private accomodation. Besides that initial ethnic conflicts between eco-migrants and host inhabitants ended up having a positive impact on the adaptation process. Eco-migrants who have the private property and stable jobs have a better chance for adaptation and in general, they described themselves as satisfied in their lives. Overall, the present study suggests that well-adapted eco-migrants have multiple identities, they perceive themselves as a part of a new community and at the same time, they can't forget their old "roots", as they say, which is related to their welfare.
\end{abstract}

\section{Keywords:}

Migration, eco-migration, Georgian eco-migrants, social identity, adaptation, identity transformation, adaptation strategies.

JEL Classification: 131, J68, N90 